\title{
Retrieval of the optical depth using an all-sky CCD camera
}

\author{
Francisco J. Olmo, ${ }^{1,2, \star}$ Alberto Cazorla, ${ }^{1,2}$ Lucas Alados-Arboledas, ${ }^{1,2}$ \\ Miguel A. López-Álvarez, ${ }^{4}$ Javier Hernández-Andrés, ${ }^{3}$ and Javier Romero ${ }^{3}$ \\ ${ }^{1}$ Grupo de Física de la Atmósfera, Centro Andaluz de Medio Ambiente, Universidad de Granada, \\ Junta de Andalucía, Avda. del Mediterráneo s/n, 18071 Granada, Spain \\ ${ }^{2}$ Departamento de Física Aplicada, Facultad de Ciencias, Universidad de Granada, \\ Fuentenueva s/n. 18071 Granada, Spain \\ ${ }^{3}$ Departamento de Óptica, Facultad de Ciencias, Universidad de Granada, \\ Fuentenueva s/n, 18071 Granada, Spain \\ ${ }^{4}$ Hewlett-Packard Spain, Large Format Printing Division, \\ 08174 Sant Cugat del Vallès, Barcelona, Spain \\ *Corresponding author: fjolmo@ugr.es
}

Received 29 April 2008; revised 7 October 2008; accepted 17 October 2008; posted 21 October 2008 (Doc. ID 95626); published 17 November 2008

\begin{abstract}
A new method is presented for retrieval of the aerosol and cloud optical depth using a CCD camera equipped with a fish-eye lens (all-sky imager system). In a first step, the proposed method retrieves the spectral radiance from sky images acquired by the all-sky imager system using a linear pseudoinverse algorithm. Then, the aerosol or cloud optical depth at $500 \mathrm{~nm}$ is obtained as that which minimizes the residuals between the zenith spectral radiance retrieved from the sky images and that estimated by the radiative transfer code. The method is tested under extreme situations including the presence of nonspherical aerosol particles. The comparison of optical depths derived from the all-sky imager with those retrieved with a sunphotometer operated side by side shows differences similar to the nominal error claimed in the aerosol optical depth retrievals from sunphotometer networks. (C) 2008 Optical Society of America

OCIS codes: $\quad 150.0150,100.5010,200.4260,010.3920,120.0280,010.1290$.
\end{abstract}

\section{Introduction}

There are different optical phenomena related to the interaction between light and the atmosphere that can be registered by a CCD camera. Indeed, it is possible to retrieve spectral information by analyzing the spectral characteristics of single pixels from CCD sky images $[1,2]$ that can be used to derive information about atmospheric constituents such as aerosol and clouds. Furthermore, this spectral information allows examination of the influence of such atmospheric constituents on skylight across the whole

0003-6935/08/34H182-08\$15.00/0

(C) 2008 Optical Society of America sky dome, or any other phenomena related to light and color in the open air.

To understand the Earth's radiative budget we need to determine aerosol and cloud effects on absorption and partitioning of spectral solar radiation between the surface and the atmosphere [3]. Atmospheric aerosol particles play a dual role in the climate system and the hydrologic cycle. Their first role is the interaction with solar radiation: by scattering sunlight and reflecting a fraction of it back to space aerosols cool the climate system; by absorbing sunlight in the atmosphere aerosols further cool the surface but warm the atmosphere, changing the temperature and humidity profiles and the conditions for cloud development. Their second role affects 
the hydrologic cycle: serving as cloud condensation nuclei and ice nuclei, aerosols control cloud droplet concentration and size. Higher number concentrations of submicrometer pollution aerosol tend to decrease the cloud droplet size and prevent or delay development of precipitation [4].

Variations in aerosol-cloud interactions may cause changes in precipitation patterns (to which the human civilization adapted during the last millennium), changes in cloud cover, and possible changes in the frequency of extreme events $[5,6]$. Thus, knowledge of the optical properties of atmospheric aerosol and clouds is essential for the determination of their climatic effects but is also important for the development of techniques for remote sensing of aerosol and clouds, as well as the necessary correction of atmospheric effects in satellite imagery $[7,8]$. On the other hand, there are many difficulties in evaluating the climate effects of atmospheric aerosol particles and clouds due to the great spatial and temporal variability of their concentrations and radiative properties, which explains one of the most uncertain factors for estimating future global warming [4].

In the past few decades, many methods for remote sensing of cloud and aerosol properties have been proposed using ground-based sunphotometers, aircrafts, or satellites. Remote sensing appears to be a valuable tool for characterizing the physical and optical properties of aerosol and clouds. Sunphotometry, being the most common way to characterize aerosols from the ground during daytime, gives useful information about column-integrated physical and optical properties of atmospheric aerosols. Recent advances in star photometry allow complete coverage of the daily cycle $[9,10]$. While sunphotometer networks such as AERON $\overline{E T}$ [11] or satellite estimations can solve the spatial challenge in aerosol characterization, temporal resolution remains a problem. Another problem is judging data validity: AERONET sunphotometers require a Sun view unobstructed by clouds, but cloud rejection can be difficult [12]. Ultimately, large databases require visual inspection for data accuracy. On the other hand, an interesting recent paper of Kikuchi et al. [13] shows a technique to derive the optical depth and vertical profiles of cloud microphysics using a sky radiometer and a radar system.

Sky imagery has been used lately to retrieve information on cloud cover and aerosol characterization, e.g., $[14,15,14-16]$, analyzing information regarding sky brightness provided by sky image pixels. Cazorla et al. [15] present the design of a sky imager system with a method that uses neural networks for realtime cloud classification and cloud cover estimation. This last method discriminates between clear sky and two cloud classes, making an automated realtime analysis every 5 min. Limitations of this technique include a large image training set at each location and the unsolved problem of extreme forward scattering during dust events, causing misclassifica- tion of cloudless pixels. In the first study using a CCD camera to derive aerosol optical properties of which we are aware, Cazorla et al. [16] derived aerosol optical depth (AOD) from the all-sky imager system using a neural network model and compared the results with measurements registered by a CIMEL sunphotometer. The authors show that the neural network model results are in the range of uncertainties claimed by the aerosol networks and so the allsky imager may represent an alternative to sunphotometer systems for different sites around the world.

In contrast with sunphotometer systems, CCD cameras have several advantages such as time resolution, sky spatial and angular resolution, and the absence of problems due to Sun or sky radiance alignments. However, the cameras require a solar shadow system that must cover both the lens and the CCD sensor at every moment from direct Sun and have problems with radiance calibration. An uncalibrated sky imager such as the all-sky imager can retrieve the AOD with a function approximation approach [16], but it is difficult to specify an analytical model describing the physical interpretations of atmospheric factors that influence the radiance or irradiance measurements.

In this paper we propose a procedure for retrieval of the optical depth $(550 \mathrm{~nm})$ for both cloudless and cloudy sky conditions using a CCD camera. The procedure uses sky images from the all-sky imager system (CCD camera), an algorithm to reconstruct the spectral sky radiance at zenith, and a radiative transfer model in a real-time iterative procedure. In Section $\underline{2}$ we describe the experimental site and the instrumentation used. Section 3 presents the methodology to derive AOD from the sky images by means of an iterative procedure, the retrieved spectral sky radiance at zenith, and the radiative transfer model. In Section $\underline{4}$ we show the results and conclusions and some hints regarding future applications.

\section{Experimental Site and Instrumentation}

The sky images used in this study have been measured at the radiometric station of the University of Granada, located on the rooftop of the Centro Andaluz de Medio Ambiente (CEAMA) building. Granada $\left(37.18^{\circ} \mathrm{N}, 3.58^{\circ} \mathrm{W}, 680 \mathrm{~m}\right.$ a.s.l. $)$ is a nonindustrialized, medium size city, located in southeastern Spain. The city is situated in a natural basin surrounded by mountains with the highest mountain range located at the southeast of the basin, Sierra Nevada range, including several peaks above $3000 \mathrm{~m}$ a.s.l. Near continental conditions prevailing in this site are responsible for large seasonal temperature differences, providing cool winters and hot summers.

The all-sky imager is a custom adaptation of a scientific CCD camera by QIMAGING (RETIGA $1300 \mathrm{C}$ ) and was developed in the Atmospheric Physics Group to provide images of the whole sky dome every 5 min during daytime for the purpose of cloud and aerosol characterization $[\underline{15}, \underline{16}]$ (Fig. 1). It 


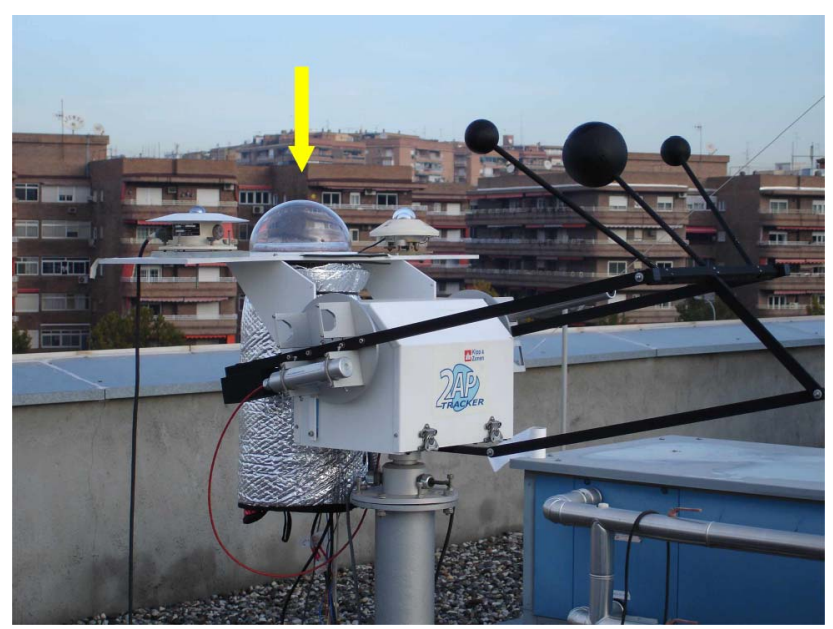

Fig. 1. (Color online) Picture of the CCD camera system and the Sun tracker.

provides full color (online) images $(1280 \times 1024$ pixels) in the three RGB channels. The camera has 12 bit digitalization per channel, therefore the final image has 36 bit digitalization and 4096 counts per channel. The lens is a FUJINON CCTV fish-eye lens developed for a $2 / 3$ " format megapixel color CCD with C-mount. The field of view is $185^{\circ}$. This configuration guarantees the $180^{\circ}$ field of view projected on the CCD, and therefore the image captured shows the whole sky dome. The optical data sheet provided by the manufacturer (FUJINON TV Lens, Optical Data Reports, FE185C057HA) indicates no longitudinal or lateral chromatic aberration and the angular distortion is less than $0.45 \%$ at every angle between 0 and $180^{\circ}$. Since the distortion is so low no correction is applied to the images. The temperature is maintained constant by a Peltier system and the complete device is adapted and mounted on a 2AP Sun Tracker/Positioner by Kipp and Zonen that follows the Sun and projects shade onto the all-sky imager to prevent stray light. The control software that automates image acquisition has been developed in the group and sets camera parameters including exposure time, gain, and offset. The images are processed in real time and both processed images and results (percent of cloud and oktas) are stored on the computer. A remote real time visualization of the images and results is now available (http://cloudcamera.ugr.es).

In order to characterize the spectral AOD we used a sunphotometer CE-318 (CIMEL Electronic, France), which is the standard Sun/sky photometer used in the AERONET network [11]. The photometer performs measurements of direct irradiance with a $1.2^{\circ}$ full field at $340,380,440,675,870,940$, and $1020 \mathrm{~nm}$ (nominal wavelength); and also measures sky radiance at $440,670,870$ and $1020 \mathrm{~nm}$ by means of almucantar (setting zenith angle and varying the azimuth angle) and principal plane (setting solar azimuth angle and varying the zenith angle) configurations. The filters used were ion-assisted deposition interference filters with bandpass (full width at half-maximum) of the $340 \mathrm{~nm}$ channel at $2 \mathrm{~nm}$ and the $380 \mathrm{~nm}$ filter at $4 \mathrm{~nm}$, while the bandpass of all other channels was $10 \mathrm{~nm}$. Since summer 2002, this instrument has been operated by our research team using our own methodology [17]. In late 2004 the instrument was incorporated to the AERONET network. Calibration of the instrument was performed at Sierra Nevada (2200 m a.s.l) at least twice per year by the Langley plot technique (e.g., $[18,19])$. Additionally, an integrating sphere has been used to calibrate the instrument for radiance measurements [18]. The total uncertainty in AOD and sky radiance measurements are about $0.01 \%$ and $5 \%$, respectively [11]. The measurements (irradiance and sky radiance) follow the AERONET schedule (http:// aeronet.gsfc.nasa.gov/).

\section{Methodology}

We have developed a real-time iterative procedure applied to the sky images registered by the all-sky imager involving (a) cloud classification of pixels derived by a neural network, (b) reconstructing spectral sky radiance at zenith by linear pseudoinverse spectral estimation algorithm [20], and (c) deriving the optical depth at $550 \mathrm{~nm}$ using radiative transfer code.

As a first step, the algorithm analyzes and classifies the image pixels as cloudy or cloudless. In a previous work [15] we developed real-time software to determine cloud classification from the raw images. The algorithm uses a multilayer perceptron technique and was improved using a genetic algorithm. The cloud classification method uses three parameters as input: mean of the pixel and its neighbors in the red and blue channels and the variance of the pixel and its neighbors in the red channel. The output parameters extracted from the sky images are percent of opaque clouds, percent of thin clouds, oktas for opaque and thin clouds, percent of opaque and thin clouds in every octant, and Sun position in octant. The error in pixel classification is $15 \%$ [15]. Thus, this real time software classifies the zenith zone as cloudless or cloudy. Figure 2 shows an example of a sky image captured and processed by the system.

In a second step, using the images registered by the all-sky imager we obtain real-time skylight radiances (spectral power distribution) at zenith, from 380 to $780 \mathrm{~nm}$, by means of the linear pseudoinverse spectral estimation algorithm that we have found fast, robust to noise and with excellent results (e.g., $[2,20,21])$. The pseudoinverse algorithm provides a spectral radiance for each pixel in a $1280 \times 1024 \mathrm{im}$ age in real time and requires a training data set. The selection of training data set has been based on grouping similar spectral radiances according to their distances measured by the colorimetric and spectral combined metric [1,2]. In [2] the authors evidenced the goodness of this retrieval procedure. The advantage of this synthesis algorithm compared with others used with CCD cameras is that the method is very appropriate for noncalibrated imaging systems 


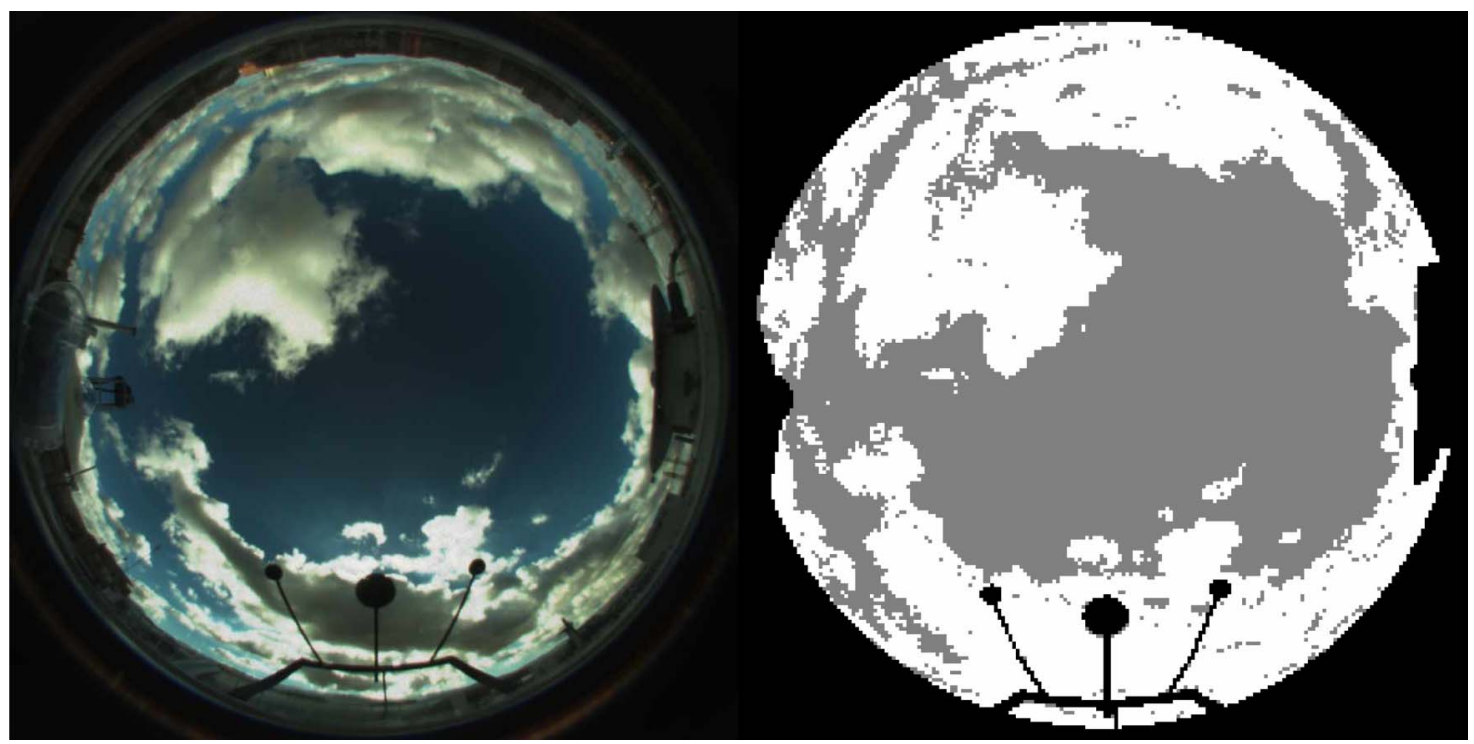

Fig. 2. (Color online) Sky image example captured and processed by the system.

where spectral responsivities of the sensors are unknown $[2,20]$. Finally, using the registered sky images, the method shows that it is possible to recover zenithal sky radiance spectra with the reduced number of broadband spectral filters used in the CCD camera. To check the accuracy of the spectral zenith radiances retrieved by the linear pseudoinverse method [2], we have measured simultaneously spectral skylight radiances using a SpectraScan PR650 spectroradiometer. The retrieved skylight SPDs is very accurate in all cases, proving the reliability of the linear pseudoinverse method to obtain spectral information from CCD sensor responses. Figure 3 shows an example of sky image captured by the all-sky imager and the zenithal spectral radiance retrieved by the spectral estimation algorithm.

In a third step, to extract aerosol (AOD $550 \mathrm{~nm}$ ) or cloud (COD $550 \mathrm{~nm}$ ) optical information we used radiative transfer code that assesses the spectral sky radiance at different combinations of zenith and azimuthal angles using the optical depth and other local atmospheric parameters as input. We perform an iterative procedure to match the zenithal spectral radiances reconstructed by the linear pseudoinverse method (sky images) with those output by the radiative transfer code. The result of this iterative process is the AOD $550 \mathrm{~nm}$ or the COD $550 \mathrm{~nm}$. The optimal optical depth at $550 \mathrm{~nm}$ (output value) is retrieved if the residuals between radiances-for all wavelengths-are less than $10 \%$.

The radiative transfer code is the Santa Barbara DISORT Atmospheric Radiative Transfer (SBDART [22]), a software tool that computes plane-parallel radiative transfer in clear and cloudy conditions within the Earth's atmosphere and at the surface. The code uses a discrete ordinate module (low resolution atmospheric transmission model) that provides a numerically stable algorithm to solve the equations [23], and Mie scattering results for light scattering by aerosol, water droplets, and ice crystals. SBDART can compute the radiative effects of several aerosol types that can be simulated using
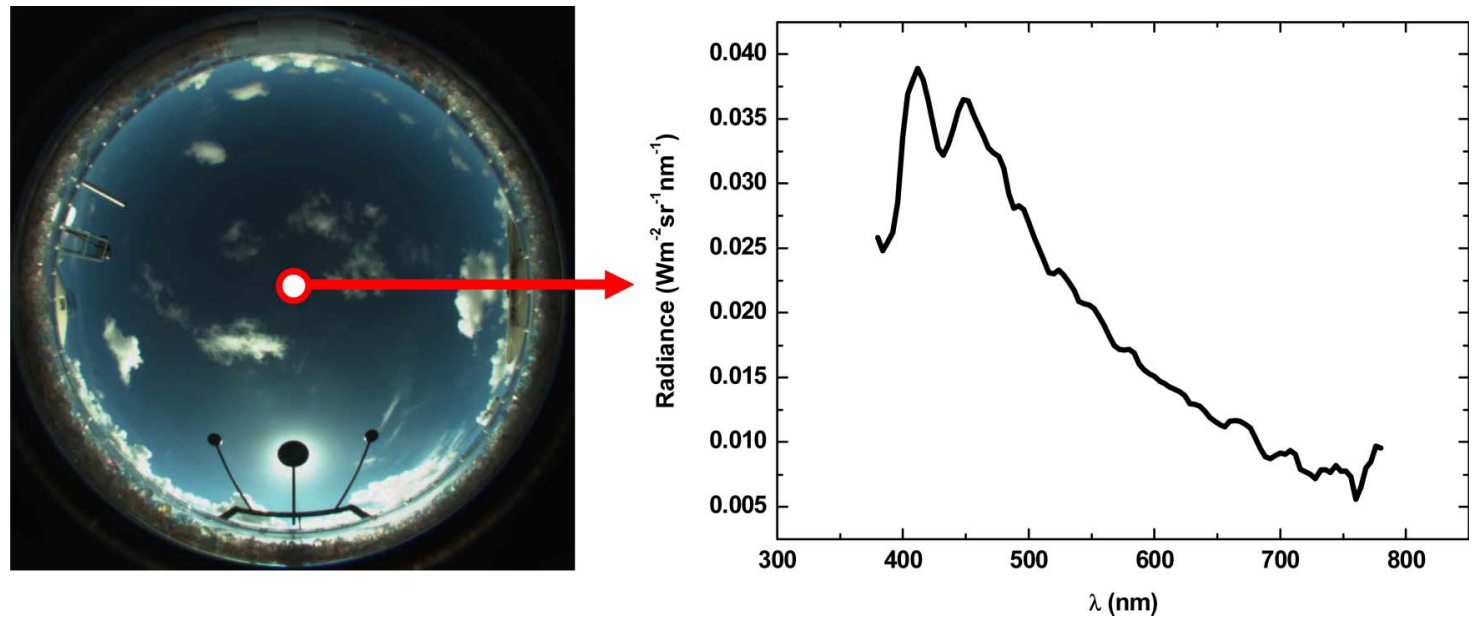

Fig. 3. (Color online) Sky image example captured and zenithal spectral radiance assessed by the linear pseudoinverse algorithm. 
standard aerosol models. The aerosol extinction efficiency, single-scattering albedo, and asymmetry parameter required for the computation of the radiative transfer are computed using a Mie scattering code. Moreover, the asymmetry factor is used to generate a scattering phase function through the Henyey-Greenstein approximation. The columnar optical depth is derived from user-specified horizontal data and an internal vertical distribution model following exponential profiles with differing density scale heights. The extinction efficiency, singlescattering albedo, and asymmetry parameter required for the computation of radiative transfer within a cloudy atmosphere are also computed using Mie scattering code for spherical cloud droplets with a modified gamma size distribution. To allow analysis of radiative transfer through cirrus clouds, the code also includes scattering parameters for spherical ice grains of a single size distribution [22]. All important processes that affect ultraviolet, visible, and infrared radiation fields are included. The U.S. midlatitude standard atmosphere model was adopted to simulate the transmitted solar irradiance and radiance observed at the ground, and the underlying surface is assumed to be Lambertian with albedo 0.15. Previous studies [17] have shown this value of surface albedo as the best choice in our study area. The mid-latitude standard atmosphere has been widely used by the atmospheric research community and provides standard vertical profiles of pressure, temperature, water vapor, and ozone density. The ozone column contents were taken from Total Ozone Mapping Spectrometer values (http://toms.gsfc.nasa.gov). The code was validated in the spectral range of solar and terrestrial radiation with excellent results for the different radiative processes that take place in the atmosphere [22], and therefore, the spectral surface irradiance or sky radiance can be appropriately computed under different atmospheric conditions.

To evaluate the methodology, first we conducted different experimental campaigns during June-October 2006 and July-November 2007, including cloudy and cloudless sky conditions. We used a CIMELCE318 sunphotometer that allowed us to derive directly the AOD at the indicated wavelengths and the Angström alpha parameter, following the procedure described in Alados-Arboledas et al. [24], and consequently, we could assess the AOD and COD $(550 \mathrm{~nm})$.

\section{Results and Conclusions}

To check the accuracy of the third step, Fig. 4 shows the zenithal spectral radiance curves reconstructed by the linear pseudoinverse algorithm (measured) compared with the results of the iterative process (calculated using the SBDART radiative transfer code) for two selected cases: (a) a day affected by a Saharan dust event, 10 July 2006, and (b) a day with low aerosol load, 31 October 2006. As we can see, both methodologies agree, and as demonstrated by LópezÁlvarez et al. [2], the spectral radiance reconstructed
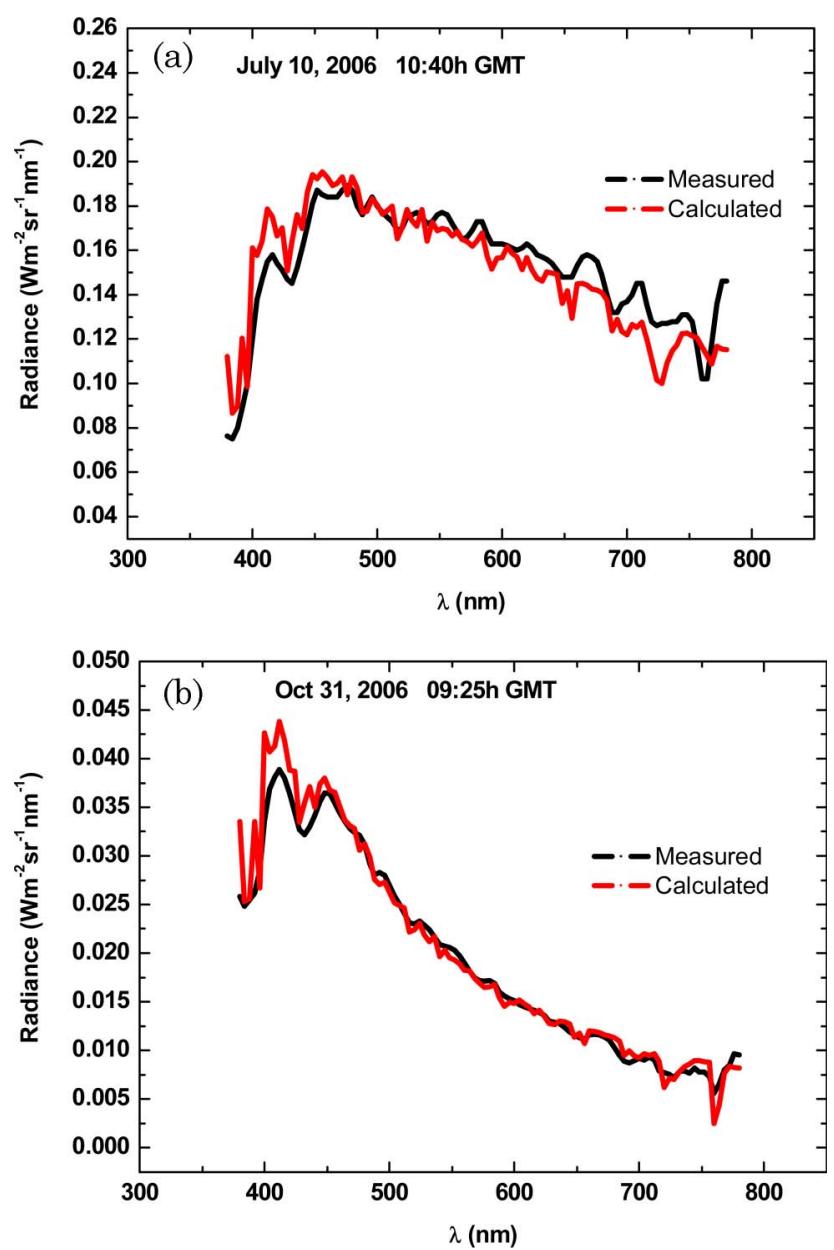

Fig. 4. (Color online) Zenithal spectral radiance curves calculated by the linear pseudoinverse algorithm (measured) and compared with the results using the radiative transfer code (calculated) for two selected cases: (a) Saharan dust event and (b) low aerosol load.

using the image captured and the linear pseudoinverse method also agree with spectroradiometer zenith radiance measurements (residuals $<10 \%$ ). The spectral differences observed in Fig. 4(a) are probably due to the atmospheric aerosol hypothesis underlying the radiative transfer code. This code uses a spherical particles approximation (Mie theory) to calculate, through the iterative inversion procedure, the effective single-scattering albedo and asymmetry parameter. After that the radiative transfer code uses the retrieved asymmetry parameter to generate a scattering phase function, through the HenyeyGreenstein approximation, that finally is used to compute the sky radiance. It must be pointed out that the spherical particles approximation is less reliable for radiance computations that involve dust aerosol particles (nonspherical particles). On 10 July 2008 [Fig. 4(a)] the atmospheric aerosol includes a high load of dust particles that present large differences between the measured and the retrieved spectral radiances. Even so, in this case the residuals are lower than $10 \%$, following our convergence criteria for the iterative procedure. 
To test also this third step for different sky conditions we selected 40 CCD images captured including clear days (low AOD), days affected by Saharan dust (high AOD), and cloudy days. We selected this data set taking into account measurements that present increasing values in optical depth. Figure 5(a) shows the spectral radiance calculated by the iterative procedure, using the radiative transfer code, versus the spectral radiance reconstructed ("measured") by the linear pseudoinverse method, and Fig. 5(b) shows the histogram of differences between the reconstructed and the calculated zenith spectral radiances. The mean bias deviation (MBD) is about $5 \mathrm{Wm}^{2} \mathrm{sr}^{-1}$ and the root mean square deviation (RMSD) is about $0.08 \mathrm{Wm}^{2} \mathrm{sr}^{-1}$. Thus, the model has an overestimation of about $6 \%$. In addition, Fig. 5(b) reveals that more than $90 \%$ of the calculated values have deviations less than $10 \mathrm{Wm}^{2} \mathrm{sr}^{-1}$.

To assure homogeneity in almucantar sky radiance measurements used as input in inversion codes to de-
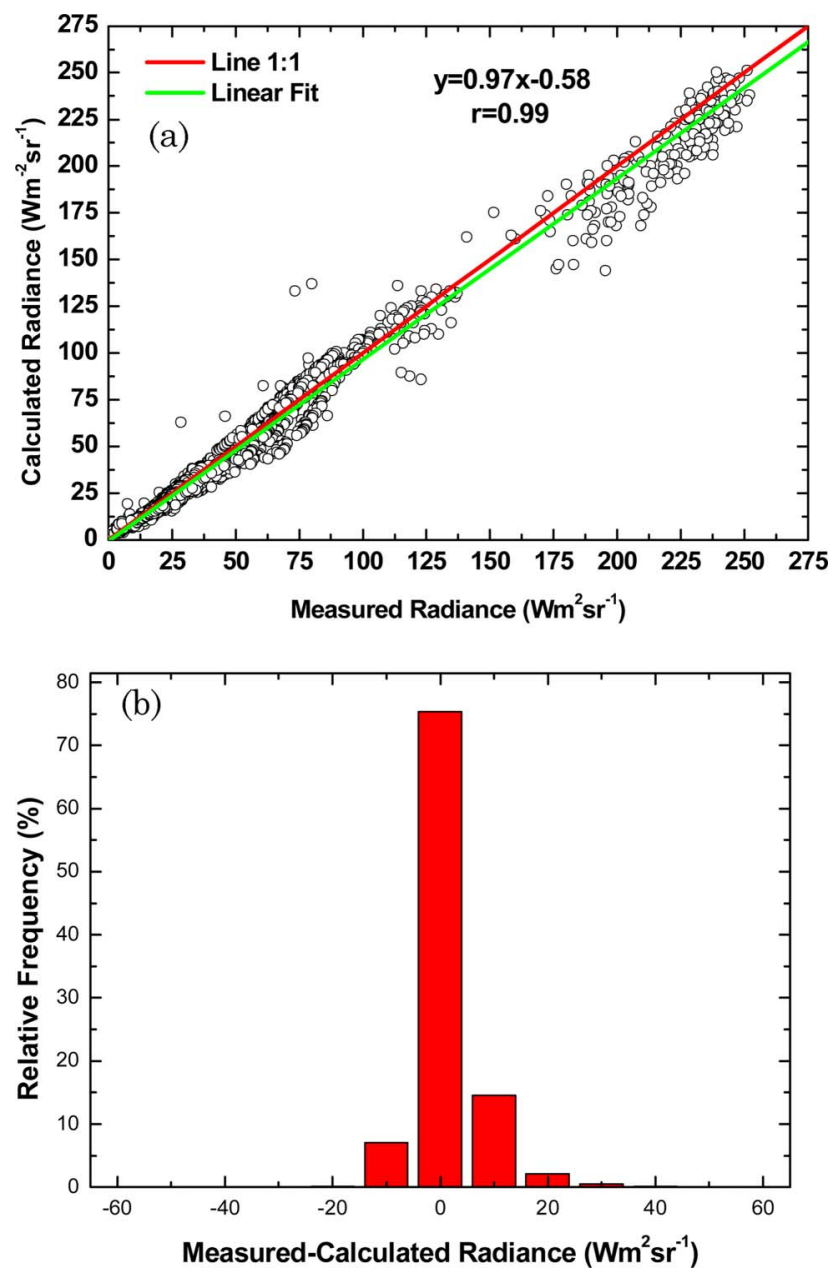

Fig. 5. (Color online) (a) Spectral radiance calculated by the iteration procedure, using the radiative transfer code, versus the spectral radiance reconstructed by the linear pseudoinverse spectral algorithm. (b) Histogram of the differences between the reconstructed and the calculated zenith spectral radiances. Both figures include all individual radiance values from 380 to $780 \mathrm{~nm}$ corresponding to the selected data sets. rive the aerosol optical properties for cloudless skies, previous authors accepted sky radiance errors about $10 \%$ (e.g., $[17,25,26])$. Thus, considering the results of López-Âlvarez et al. [2] and the results of this paper, we can hypothesize that this methodology is very effective in reconstructing the spectral sky radiance. Also, it would be possible to use these results in inversion codes to estimate other aerosol optical properties such as particle size distributions, singlescattering albedo or asymmetry parameter.

Figures 6(a) and 6(b) show the time evolution of AOD and COD $(5 \overline{50 \mathrm{~nm}})$, including experimental values estimated using the CIMEL sunphotometer and values calculated by the iterative algorithm, for two successive days, 30 and 31 October 2006, with alternating clear and cloudy conditions. These results show the ability of this methodology to derive the optical depth for different sky conditions, including different cloud covers.

Figure 7 shows the histograms of differences between experimental (sunphotometer CIMEL values) and calculated optical depth values for the
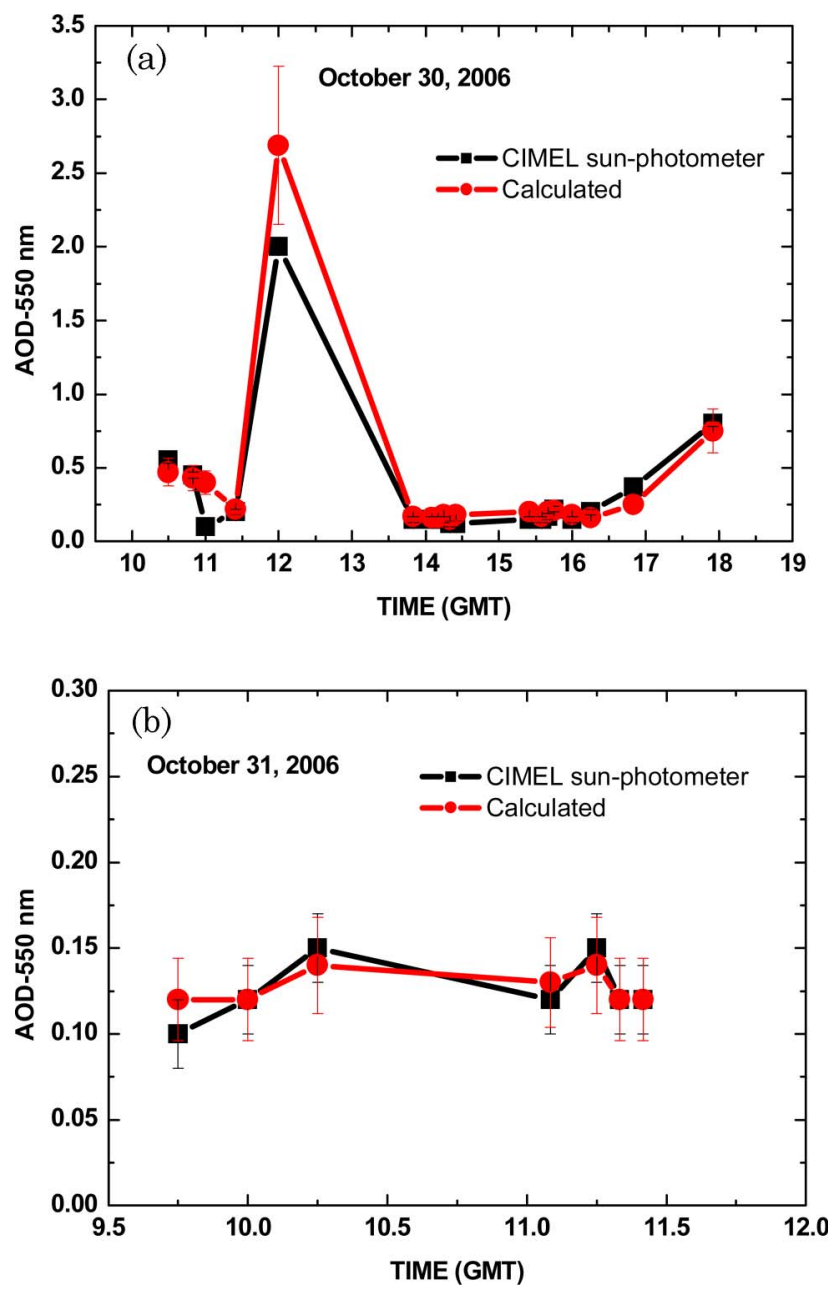

Fig. 6. (Color online) Optical depth $(550 \mathrm{~nm})$ time evolution (experimental values using the CIMEL sunphotometer and calculated values using the iterative algorithm): (a) 30 October 2006 and (b) 31 October 2006. 


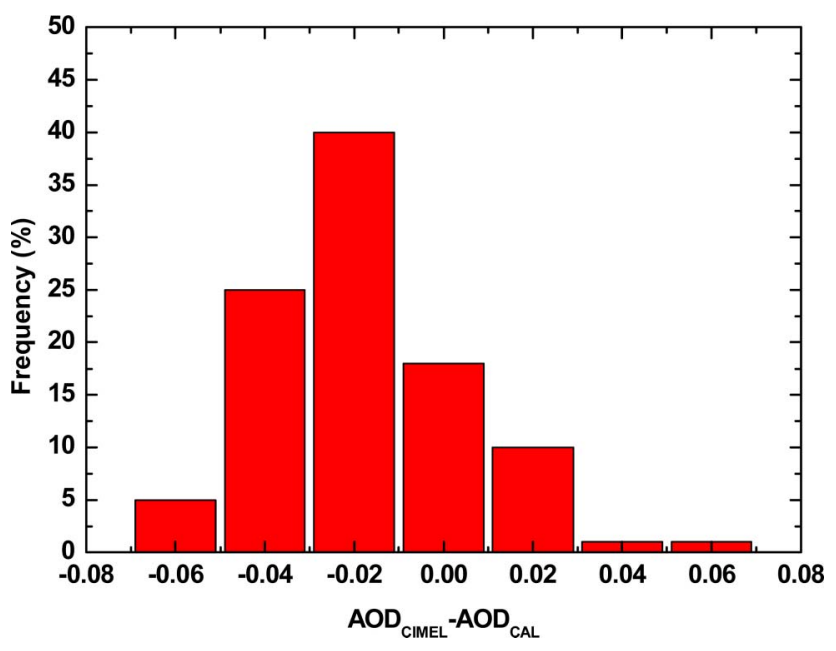

Fig. 7. (Color online) Histogram of the differences between experimental (sunphotometer CIMEL values) and calculated optical depth values for the complete data set.

complete data set. This figure reveals that $80 \%$ of the calculated values have a deviation of less than 0.04 and $60 \%$ have a deviation of less than 0.02 . This threshold in the deviation is near the nominal error in the AOD retrievals claimed in the AERONET network [11]. The overall performance is rather good with a slight overestimation of $2.9 \%$ (MBD) and an RMSD close to $3.7 \%$. The experimentally calculated scatterplot (not shown in the paper) shows a slight overestimation for low optical depth values and underestimation for high optical depth values. Analyzing the spectral radiance results (Fig. 4), we can conclude that the methodology overestimates the spectral radiance values at wavelengths close to $400 \mathrm{~nm}$ for cloudless conditions and underestimates the spectral radiance values at wavelengths larger than $550 \mathrm{~nm}$ for cloud conditions. These results are probably due to the use of the Henyey-Greenstein parameterization for the phase function in radiative transfer code, which is probably less reliable for radiance computations [22] either during dust events or for different cloud types.

The RMSD and MBD values obtained in this study are slightly larger than those obtained by Cazorla et al. [16] in their retrieval of AOD from CCD images by means of neural networks. Nevertheless, the methodology presented here provides better results for cases with large aerosol load when the neural network methodology [16] has large errors. One of the main problems in neuronal network design is the election of the training set and its classification. The neuronal networks' models are very sensitive to the training set. It is important to select a wide variety of sky conditions and classify them properly. As a consequence, the use of the neuronal network technique at different locations requires repeating the training process as well. The main weakness of the neuronal network classification of sky images is found in the circumsolar area $[15,16]$, and the solution may be difficult. In fact, the large brightness of the circumsolar area produces saturation of the associated pixels in the image and blinds the imager. In addition, these methods need a perfect spatial calibration of the all-sky imager [16]. In this sense, the methodology presented in this paper could solve the strong forward scattering problems associated with the large particle load in neural networks methodology. In addition, with this methodology, as the only training set concerns the spectral sky radiance reconstructions, we do not need an absolute radiance calibration, and the training set does not depend on the location.

This work was supported by the Spanish Ministry of Science and Technology through project CGL200766477-C02-01 and by the Andalusian Regional Government through projects P06-RNM-01503 and P08RNM-3568. This research was also funded by the Spanish Ministry of Education and Science and the European Fund for Regional Development (FEDER) through grant FIS2007-60736. We also are especially thankful to Andrew Kowalski who revised the manuscript.

\section{References}

1. M. A. López-Álvarez, J. Hernández-Andrés, J. Romero, and R. L. Lee, Jr., "Designing a practical system for spectral imaging of skylight," Appl. Opt. 44, 5688-5695 (2005).

2. M. A. López-Álvarez, J. Hernández-Andrés, J. Romero, F. J. Olmo, A. Cazorla, and L. Alados-Arboledas, "Using a trichromatic CCD camera for spectral skylight estimation," Appl. Opt. 47, H31-H38 (2008).

3. Y. J. Kaufman, D. Tanré, B. N. Holben, S. Mattoo, L. A. Remer, and T. F. Eck, "Aerosol radiative impact on spectral solar flux at the surface, derived from principal plane sky measurements," J. Atmos. Sci. 59, 635-646 (2002).

4. P. Forster, V. Ramaswamy, P. Artaxo, T. Berntsen, R. Betts, D. W. Fahey, J. Haywood, J. Lean, D. C. Lowe, G. Myhre, J. Nganga, R. Prinn, G. Raga, M. Schultz, and R. Van Dorland, "Changes in atmospheric constituents and in radiative forcing," in Climate Change 2007: The Physical Science Basis. Contribution of Working Group I to the Fourth Assessment Report of the Intergovernmental Panel on Climate Change, S. Solomon, D. Qin, M. Manning, Z. Chen, M. Marquis, K. B. Averyt, M. Tignor, and H. L. Miller, eds. (Cambridge U. Press, 2007).

5. D. Tanré, Y. Kaufman, T. Nakajima, and V. Ramanathan, "Preface to special section on global aerosol system," J. Geophys. Res. 110, D10S01 doi: 10.1029/2004JD005724 (2005).

6. H. Lyamani, F. J. Olmo, A. Alcántara, and L. AladosArboledas, "Atmospheric aerosols during the 2003 heat wave in southeastern Spain I: spectral optical depth," Atmos. Environ. 40, 6453-6464 (2006).

7. C. Sánchez, F. J. Olmo, and L. Alados-Arboledas, "Determination of aerosol optical thickness from measurements of spectral sky radiance," J. Aerosol Sci. 29, 1199-1211 (1998).

8. Y. J. Kaufman, D. Tanré, and O. Boucher, "A satellite view of aerosols in the climate system," Nature 419, 215-223 (2002).

9. D. Pérez-Ramírez, J. Aceituno, B. Ruiz, F. J. Olmo, and L. Alados-Arboledas, "Development and calibration of a star photometer to measure the aerosol optical depth: smoke observations at a high mountain site," Atmos. Environ. 42 , 2733-2738 (2008).

10. D. Pérez-Ramírez, B. Ruiz, J. Aceituno, F. J. Olmo, and L. Alados-Arboledas, "Application of Sun/star photometry to 
derive the aerosol optical depth,” Int. J. Remote Sens. 29, 5113-5132 (2008).

11. B. N. Holben, T. F. Eck, I. Slutsker, D. Tanre, J. P. Buis, A. Setzer, E. Vermote, J. A. Reagan, Y. J. Kaufman, T. Nakajima, F. Lavenu, I. Jankowiak, and A. Smirnov, "AERONET-a federated instrument network and data archive for aerosol characterization," Remote Sens. Environ. 66, 1-16 (1998).

12. A. Smirnov, B. N. Holben, T. F. Eck, O. Dubovik, and I. Slutsker, "Cloud-screening and quality control algorithms for the AERONET database," Remote Sens. Environ. 73, 337-349 (2000).

13. N. Kikuchi, T. Nakajima, H. Kumagai, H. Kuroiwa, A. Kamei, R. Nakamura, and T. Y. Nakajima, "Cloud optical thicness and effective particle radius derived from transmitted solar radiation measurements: comparison with cloud radar observations," J. Geophys. Res. 111, D07205, doi:10.1029/ 2005JD006363 (2006).

14. C. N. Long, J. M. Sabburg, J. Calbó, and D. Pagès, "Retrieving cloud characteristics from ground based daytime color all-sky images," J. Atmos. Ocean. Technol. 23, 633-652 (2006).

15. A. Cazorla, F. J. Olmo, and L. Alados-Arboledas, "Development of a sky imager for cloud cover assessment," J. Opt. Soc. Am. A 25, 29-39 (2008).

16. A. Cazorla, F. J. Olmo, and L. Alados-Arboledas, "Using a sky Imager for aerosol characterization," Atmos. Environ. 42, 2739-2745 (2008).

17. F. J. Olmo, A. Quirantes, A. Alcántara, H. Lyamani, and L. Alados-Arboledas, "Preliminary results of a nonspherical aerosol method for the retrieval of the atmospheric aerosol optical properties," J. Quant. Spectrosc. Radiat. Transf. 100, 305-314 (2006).

18. A. Alcántara-Ruiz, F. J. Olmo, and L. Alados-Arboledas, "Langley calibrations of sunphotometer at Sierra Nevada, Granada, Spain," Opt. Pura Apl. 37, 3263-3269 (2004).

19. V. Estellés, M. P. Utrillas, J. A. Martínez-Lozano, A. Alcántara, L. Alados-Arboledas, F. J. Olmo, J. Lorente, X. de Cabo,
V. Cachorro, H. Horvath, A. Labajo, M. Sorribas, J. P. Díaz, A. M. Díaz, A. M. Silva, T. Elías, M. Pujadas, J. A. Rodrigues, J. Cañada, and Y. García, "Intercomparison of spectroradiometers and sunphotometers for the determination of the aerosol optical depth during the VELETA-2002 field campaign,” J. Geophys. Res. 111, D17207, doi: 10.1029/ 2005JD006047 (2006).

20. M. A. López-Álvarez, J. Hernández-Andrés, E. M. Valero, and J. Romero, "Selecting algorithms, sensors, and linear bases for optimum spectral recovery of skylight," J. Opt. Soc. Am. A 24, 942-956 (2007).

21. J. L. Nieves, E. M. Valero, S. M. C. Nascimento, J. HernándezAndrés, and J. Romero, "Multispectral synthesis of daylight using a commercial digital CCD camera," Appl. Opt. 44, 5696-5703 (2005).

22. P. Ricchiazzi, S. Yang, C. Gautier, and D. Sowle, "SBDART: A research and teaching software tool for plane-parallel radiative transfer in the Earth's atmosphere," Bull. Amer. Meteorol. Soc. 79, 2101-2113 (1998).

23. K. Stamnes, S. C. Tsay, W. Wiscombe, and K. Jayaweera, "Numerically stable algorithm for discrete-ordinatemethod radiative transfer in multiple scattering and emitting layered media," Appl. Opt. 27, 2502-2509 (1988).

24. L. Alados-Arboledas, H. Lyamani, and F. J. Olmo, "Aerosol size properties at Armilla, Granada (Spain)," Q. J. R. Meteorol. Soc. 129, 1395-1413 (2003).

25. O. Dubovik, B. N. Holben, T. Lapyonok, A. Sinyuk, M. I. Mishchenko, P. Yang, and I. Slutsker, "Non-spherical aerosol retrieval method employing light scattering by spheroids," Geophys. Res. Lett. 29, 1415 (2002).

26. F. J. Olmo, A. Quirantes, V. Lara, H. Lyamani, and L. Alados-Arboledas, "Aerosol optical properties assessed by an inversion method using the solar principal plane for nonspherical particles," J. Quant. Spectrosc. Radiat. Transfer 109, 1504-1516 (2008). 